\title{
Duration of periventricular densities in preterm infants and neurological outcome at 6 years of age
}

\author{
Marian Jongmans, Sheila Henderson, Linda de Vries, Lilly Dubowitz
}

\begin{abstract}
Parenchymal echogenicities that break down into extensive cystic lesions are generally followed by severe motor deficit. However, the effect of echodensities in the periventricular white matter, so called 'flares', on later development is less well documented. The aim of the present study was to investigate the impact of neonatal flares in preterm infants on neurological status and motor competence at 6 years of age and to see to what extent outcome was related to duration of flares. Forty four children with flares, subdivided into three groups according to the duration of flares, and 62 children with normal scans were assessed on Touwen's neurological examination, the Movement ABC, and the British Ability Scales. No differences in cognitive abilities were found between the groups. The results of the motor assessments showed that performance decreased significantly with increasing duration of flares. In addition, there was a suggestion that this trend was stronger in measures assessing lower limb function than those of upper limb. Teachers were also able to identify differences between the groups of children on the basis of their motor performance in school.

(Arch Dis Child 1993; 69: 9-13)
\end{abstract}

Over the last 20 years, numerous studies have been published that attempt to relate lesions diagnosed by brain imaging to later development. It is well documented that parenchymal echogenicities that break down into extensive cystic lesions (periventricular and subcortical leukomalacia) are almost invariably followed by severe motor deficit. ${ }^{1}$ However, the consequences of echodensities in the periventricular white matter, so called 'flares', which either break down into small localised cysts or resolve completely are much less clear. In particular, little is known about the extent to which the duration of the flares influences later outcome.

In a prospective study, Trounce et al considered densities only to be relevant if they were present for at least 14 days. ${ }^{2}$ However, they provided no empirical evidence to support their view that flares that resolve earlier do not produce any impairment. In contrast, De Vries et al found that flares lasting for less than two weeks did affect early neurological status in some children. ${ }^{3}$ In this study $46 \%$ of the children with flares lasting between 6 and 9 days and $65 \%$ of the children with flares lasting for 10 days or longer showed subtle neurological abnormalities (for example dystonia).
In addition, four children in the latter group developed spastic diplegia. Appleton et al reported similar findings in a smaller study. ${ }^{4}$ In all three of the above studies the children were followed up for three years or less.

Two recent publications have extended our knowledge of the consequences of flares by reporting outcome at 5 years of age. ${ }^{56}$ Both of these studies report data on motor and intellectual performance. Fawer and Calame found children with small focal periventricular leukomalacia to be significantly less competent in their performance on the McCarthy Motor Scale than those with normal scans. In contrast, Levene et al could not detect a statistical significant difference in performance between children with prolonged flares and those with normal ultrasound scans on the Test of Motor Impairment. However, the studies differ in that most children with flares in Fawer and Calame's study had an additional haemorrhage while Levene et al explicitly excluded children with haemorrhages from their 'prolonged' flares group. In both of these studies, a cut off point of 14 days was adopted as the criterion for prolonged flares.

The aim of the present study was to investigate the impact of flares on neurological status and perceptuomotor competence at 6 years of age and to explore further the extent to which the duration of flares was related to the severity of outcome. In contrast to previous studies, children were not only examined in a standard test situation but their performance on every day life activities in school was also evaluated.

\section{Patients and methods}

\section{PATIENTS}

The 106 children described in the current study formed a subset of prematurely born children enrolled in a prospective follow up study designed to examine the relationship between early neurological status and later development. Children were selected for the main study if they fulfilled the following criteria: (i) gestational age of 34 weeks or less, (ii) a minimum of three consecutive ultrasound scans at least 24 hours apart in the neonatal period, (iii) at least one follow up evaluation at either 40 weeks' postmenstrual age or in infancy at $6,9,12,18$, or 24 months on a neurodevelopmental examination, and (iv) no congenital abnormalities.

On the basis of this selection, 219 of the children admitted to the Hammersmith Hospital neonatal intensive care unit between January 1984 and February 1986 were eligible for inclusion. At 6 years of age 174 children participated in our main study. Twenty nine 
children (13\%) were lost to follow up and a further $16(8 \%)$ had disabilities that were sufficient to render them unexaminable by the techniques we had chosen to use.

\section{ULTRASOUND SCANS AND THEIR \\ CLASSIFICATION}

Scans were performed daily during the first week of life and twice a week thereafter until discharge, with an ATL Mark III mechanical sector scanner fitted with a 5 or $7.5 \mathrm{MHz}$ transducer. Whenever possible a $7.5 \mathrm{MHz}$ transducer was used to obtain the best possible resolution. Lesions were classified as haemorrhages or periventricular densities. The grading used was as described by De Vries et al. ${ }^{78}$ Unilateral or bilateral areas of increased echogenicity which were present on at least three scans were diagnosed as periventricular densities. All ultrasound scans were assessed by one author (LdV).

\section{FOLLOW UP ASSESSMENTS}

Evaluation of children in the main study included formal assessments of neurological, perceptuomotor, and cognitive functioning as well as various measures of the child's behaviour at home and at school. For the neurological assessment Touwen's Examination of the Child with Minor Neurological Dysfunction was used. ${ }^{9}$ Vision was evaluated by Sonksen-Silver's Acuity System ${ }^{10}$ and the Stereo Test. ${ }^{11}$ The perceptuomotor assessments consisted of the test and checklist from the Movement Assessment Battery for Children (formerly the Test of Motor Impairment, ${ }^{12}$ the Development Test of Visual-Motor Integration, ${ }^{13}$ and a number of more experimental measures of performance. Cognitive ability was assessed using the short form of the British Ability Scales (BAS) ${ }^{14}$ and both parents and teachers completed the appropriate Rutter Scales. ${ }^{1516}$ As one of the primary aims of the main study was to obtain detailed profiles of children's performance and to compare these with parental and teachers' observations, no attempt was made to obtain a global report on the 29 children who were lost to follow up.

As the main focus of the present study was on neurological and perceptuomotor competence, only the data from Touwen's neurological examination and the Movement $A B C$ Test and Checklist will be reported here. The children's scores on the BAS are provided as background. Other findings such as those relating to patterns of development over the six year period will be reported elsewhere.

NEUROLOGICAL EXAMINATION

All children were assessed by the same paediatrician (LD) on Touwen's examination. This was administered in full, with the exception of the items concerned with the visual system and assessment of the abdominal skin reflex as no consistent finding could be elicited from it. This left 46 optimality items out of the 55 originally proposed by Touwen. A low optimality score (minimum $=0$ ) indicates nonoptimal performance, while a high score (maximum $=46$ ) indicates optimal performance. In addition to evaluating the total optimality score, performance on the nine clusters of items were examined separately. Touwen described these clusters as: sensorimotor apparatus, posture, balance of trunk, coordination of extremities, fine manipulation, dyskinesia, gross motor functions, quality of movement, and associated movements.

\section{PERCEPTUOMOTOR COMPETENCE}

Perceptuomotor competence was assessed using the Movement ABC. This battery has two components: the Movement ABC Test (an update of the Test of Motor Impairment) and the Movement ABC Checklist to be completed by the child's teacher or therapist. During face to face testing the child is required to perform eight tasks covering the areas of manual dexterity, ball skills, and balance. Raw scores on each item are converted to normative scores on a scale extending from 0 (good) to 5 (poor) that added together produce a total score ranging from 0 to 40 .

The second part of the battery involves the child's teacher in the completion of a 48 item checklist. Each item which describes a movement activity easily observable in a classroom or playground setting is scored on a four point scale ranging from 0 (good) to 3 (poor). As some teachers did not fully complete the checklist, the number of observations made on each child differed. Consequently, for this study it was essential to use the mean score for the items completed instead of the total score as recommended in the manual.

\section{COGNITIVE ABILITIES}

Cognitive abilities were assessed using the short form of the BAS for children between the ages of 5 to 7.9 years. This includes two verbal tests involving naming vocabulary and the appreciation of similarities in the meanings of words and two non-verbal tests, digit recall and matrices.

\section{STATISTICAL ANALYSIS}

As several of the data sets obtained were not normally distributed, both parametric and non-parametric statistics were used in the analyses. To test for trends on the scores which were not normally distributed, the Jonckheere test for ordered alternatives was employed. ${ }^{17}$ Elsewhere, analysis of variance and multiple regression analyses ${ }^{18}$ were used.

\section{Results}

\section{ULTRASOUND FINDINGS}

Of the 174 children seen at 6 years of age, 62 had periventricular densities diagnosed in the neonatal period. One child had to be excluded from further study because the quality of the scans was too poor to permit determination of the duration of the flares. Of the remaining 61 
Table 1 Gestational age, birth weight, age at follow up, and cognitive abilities at 6 years of age for the four groups. Values are mean (SD)

\begin{tabular}{|c|c|c|c|c|}
\hline & $\begin{array}{l}\text { Group 1: } \\
\text { normal } \\
\text { scans } \\
(n=62)\end{array}$ & $\begin{array}{l}\text { Group 2: } \\
\text { flares } \\
<7 \text { days } \\
(n=13)\end{array}$ & $\begin{array}{l}\text { Group 3: } \\
\text { flares } \\
7-14 \text { days } \\
(n=18)\end{array}$ & $\begin{array}{l}\text { Group } 4: \\
\text { flares } \\
>14 \text { days } \\
(n=13)\end{array}$ \\
\hline $\begin{array}{l}\text { Birth weight (g) } \\
\text { Gestational age (weeks) } \\
\text { Age at follow up (months) } \\
\text { Short form BAS at } 6 \text { years }\end{array}$ & $\begin{array}{c}1410(377) \\
31(2) \\
76(3) \\
107(11)\end{array}$ & $\begin{array}{l}1349(486) \\
31(2) \\
75(2) \\
110(14)\end{array}$ & $\begin{array}{c}1345(379) \\
30(2) \\
76(3) \\
108(12)\end{array}$ & $\begin{array}{c}1142(439) \\
29(2)^{\star} \\
75(2) \\
106(10)\end{array}$ \\
\hline
\end{tabular}

*One way analysis of variance $(F=4 \cdot 67 ; p=0 \cdot 004)$.

Table 2 Neurological status at 6 years of age. Values are median (range)

\begin{tabular}{lclll}
\hline & $\begin{array}{l}\text { Group 1: } \\
\text { nomal } \\
\text { scans } \\
(n=62)\end{array}$ & $\begin{array}{l}\text { Group 2: } \\
\text { flares } \\
<7 \text { days } \\
(n=13)\end{array}$ & $\begin{array}{l}\text { Group 3: } \\
\text { fares } \\
7-14 \text { days } \\
(n=18)\end{array}$ & $\begin{array}{l}\text { Group 4: } \\
\text { flares } \\
(n=14 \text { days } \\
(n=13)\end{array}$ \\
\hline Total score & $40 \cdot 5(24-46)$ & $40(31-46)$ & $37(20-45)$ & $31(12-42)^{\star \star}$ \\
Sensorimotor apparatus & $9(2-9)$ & $9(7-9)$ & $9(4-9)$ & $6(3-9)$ \\
Posture & $7(1-7)$ & $7(3-7)$ & $6(3-7)$ & $4(0-7)^{\star}$ \\
Balance of trunk & $3(2-4)$ & $4(1-4)$ & $4(2-4)$ & $3(1-4)$ \\
Coordination of extremities & $4(0-5)$ & $3(1-5)$ & $3(2-4)$ & $2(0-4)^{\star}$ \\
Fine manipulation & $3(0-3)$ & $3(1-3)$ & $3(0-3)$ & $1(0-3)$ \\
Dyskinesia & $5(3-5)$ & $5(5-5)$ & $5(2-5)$ & $5(3-5)$ \\
Gross motor functions & $5(2-6)$ & $5(1-6)$ & $4(1-6)$ & $3(1-6)^{\star \star}$ \\
Quality of movement & $3(0-3)$ & $3(1-3)$ & $3(0-3)$ & $3(0-3)$ \\
Associated movements & $4(2-4)$ & $4(1-4)$ & $3 \cdot 5(1-4)$ & $4(1-4)$ \\
\hline
\end{tabular}

Jonckheere test for ordered alternatives ${ }^{\star \star} \mathrm{p}<0.001,{ }^{\star} \mathrm{p}<0.010$.

children, 17 children had either an additional germinal matrix $(n=8)$ or intraventricular haemorrhage grade II $(n=9)$ and these were excluded from further analysis. The remaining 44 children were then assigned to one of three groups according to the duration of echodensities. In the first, there were 13 children with flares which resolved within seven days. The second consisted of 18 children with flares which extended beyond seven days but resolved within 14 days and in the third, there were 13 children whose flares persisted for more than 14 days.

Consistently normal ultrasound scans in the neonatal period were seen in 69 children. Seven of these were excluded from the current study, five because they were found to have abnormalities that were probably genetic and two because they could not be fully assessed on the neurological examination.

Table 1 shows gestational age, birth weight, age at follow up, and cognitive abilities at 6 years for the 106 children included in this study. From the table it can be seen that there is a trend for both gestational age and birth weight to decrease with increasing duration of flares. However, only the differences between the groups on gestational age reached statistical significance $(F=4.67, p<0.004)$. Further investigation revealed that it was only those children whose flares extended beyond 14 days that were of significantly lower gestational age than the others. Also evident in this table is the similarity between the groups on the BAS $(\mathrm{F}<1 \cdot 0)$.

\section{NEUROLOGICAL OUTCOME}

The results of the neurological examinations on the four groups of 6 year olds are shown in table 2. Although there is obvious overlap between the groups, the trend towards children with longer flares showing increasing numbers of abnormal neurological signs is clearly evident. The Jonckheere test for ordered alternatives confirmed that across the four groups total optimality score decreased significantly as flare duration increased $(J=3 \cdot 71, p<0 \cdot 001)$.

Although Touwen's examination is not designed to supply clinical diagnoses of different types of motor disorder, it is of interest to note that this trend is also reflected in the number of children with a central motor deficit in the four groups. There was no child with a recognised central motor deficit among the children whose ultrasound scans were normal throughout or whose flares lasted less than seven days. In contrast, the group whose flares lasted 7-14 days contained one child with a hemisyndrome and one with a mild hemiplegia and the group with flares that lasted for at least 14 days contained three children with diplegia and one with a hemisyndrome.

When the nine clusters of items contained in the examination were considered separately, only three clusters showed a trend similar to that found for the overall optimality score (see table 2). These three clusters measured posture $(J=2 \cdot 51, p<0.01)$, coordination of the extremities $(J=2 \cdot 79, p<0 \cdot 01)$, and gross motor functioning $(\mathrm{J}=3.94, \mathrm{p}<0.001)$. In each case, it was the children whose flares lasted more than 14 days who stood out as being particularly deficient. The other clusters showed no group differences.

\section{PERCEPTUOMOTOR COMPETENCE}

Table 3 shows the children's performance on both components of the Movement ABC. As before, median scores are presented in preference to means since most distributions were not normal. In part $A$, total test scores are followed by the children's raw scores on the individual items, as these give a more direct indication of how well the children performed. When the total scores on this test were subjected to trend analysis, an identical effect to that obtained on the Touwen examination emerged. Increasingly poor performance was associated with increasing duration of flares $(J=2.97, p<0.01)$. Closer examination of the eight individual items revealed statistically significant trends for all of the items designed to assess 'static and dynamic balance' as well as for two of the 'manual dexterity' items.

\section{TEACHERS' JUDGMENTS OF MOVEMENT}

\section{COMPETENCE}

Seventy five per cent of the teachers returned the Movement ABC Checklist (49 in group 1, eight in group 2, 15 in group 3, and eight in group 4). As no significant differences were found in neurological status or perceptuomotor competence between children whose teacher did or did not return the checklist, it was considered legitimate to analyse the data for those checklists that were available. The teachers' opinions as to how well these children were coping with everyday school activities involving motor control were consistent with the observations made by both the 
Table 3 Performance on the Movement $A B C$ at 6 years. Values are median (range)

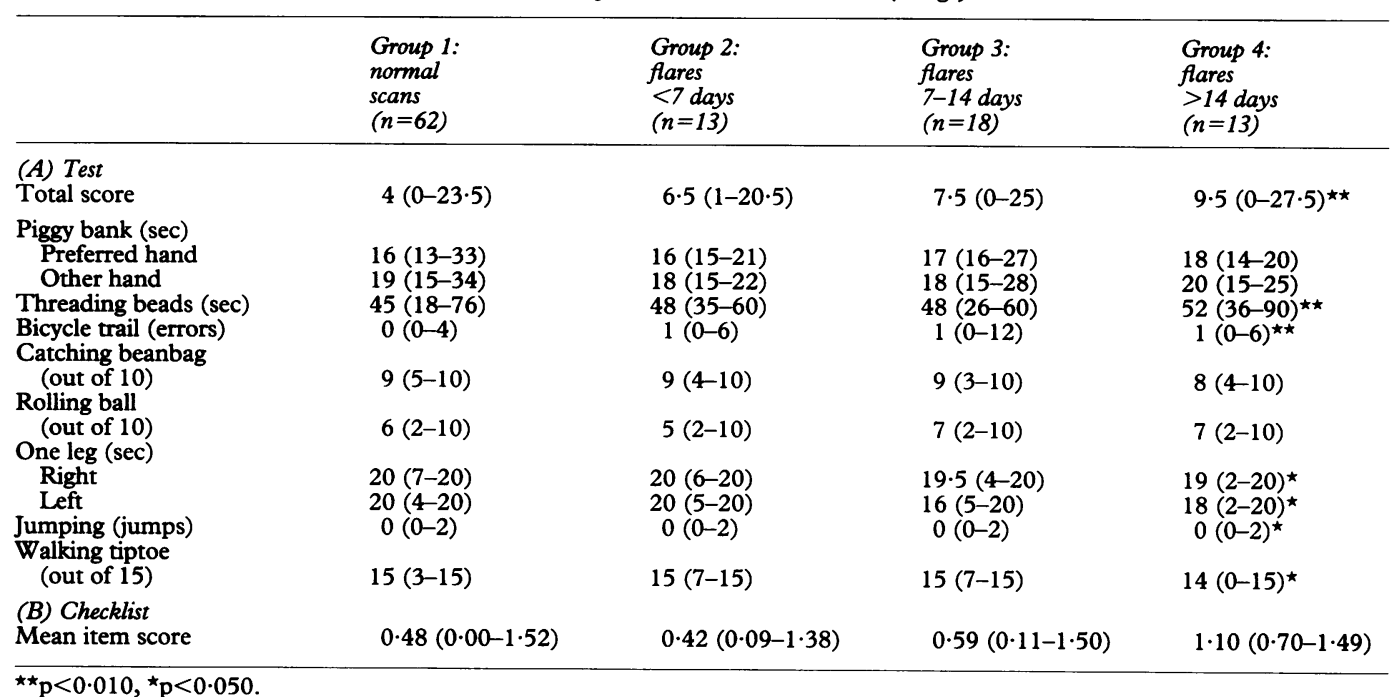

paediatrician and the psychologist (see table 3, part B). A significant overall trend of increasing mean item score was found across the four groups $(J=2 \cdot 39, \mathrm{p}<0.01)$.

OTHER VARIABLES RELATED TO OUTCOME AT 6 YEARS

As our preliminary analyses had revealed that gestational age as well as duration of flares had separated the groups, the relative importance of these variables as predictors of neurological and perceptuomotor performance was investigated using regression analysis. To achieve this a square root transformation on the measure of total neurological optimality score and the Movement ABC Test scores had first to be undertaken. For neurological optimality and competence on the Movement ABC Test, the effect of flare duration was significant ( $t$ ratios $3.08, \mathrm{p}<0.003$, and $2.49, \mathrm{p}<0.014$ respectively). On the Movement ABC Checklist, the coefficient of flares was $1.62(p=0 \cdot 110)$. When gestational age was added to the model as the second independent variable, duration of flares remained as the best predictor of neurological optimality ( $t$ ratio, $2.74, \mathrm{p}<0.01$ ), while the $t$ ratio for gestational age did not reach statistical significance $(p>0 \cdot 1)$. In contrast, for the Movement ABC Test and Checklist scores the $t$ ratios for gestational age was highly significant $(t=3.07$ and 2.69 respectively, both $\mathrm{p}<0.01)$. Thus, gestational age accounted for the greater proportion of the variance explained by the regression equations for both measures.

\section{Discussion}

This study has not only confirmed previous findings that the presence of periventricular densities is associated with later movement problems in childhood but has also demonstrated that the duration of flares is an important factor in influencing later outcome. We have also been able to show that impairment is not only detectable on formal assessments conducted by an experienced paediatrician and psychologist but is also reflected in the observation made by classroom teachers. The problems ranged from identifiable central motor deficits such as mild/moderate diplegia at the severe end of the scale to more subtle impairment, often simply labelled clumsiness.

Levene et al demonstrated by means of a multiple regression analysis that birth weight contributed more to motor competence at 5 years of age than the presence of prolonged flares. ${ }^{6}$ For two of our measures we have shown a similar relationship between the closely related variable, gestational age and performance at 6 years. From their study, Levene et al suggested that the risk of motor impairment might be more closely related to low birth weight than to the duration of flares and emphasised the need to follow up larger groups of premature infants with periventricular densities to establish whether this feature is a marker of subsequent motor impairment. While we are in agreement with Levene et al that further studies are needed to disentangle the effects of the various neonatal variables that might have a role, our results strongly suggest that persistent periventricular densities, that is mild leukomalacia, might be the mechanism by which these motor problems are produced.

First of all, we found a significant trend between poor performance on all our three motor measures and duration of flares. Secondly, by examining separately the various components of both the neurological and functional assessments we were able to demonstrate that these were most marked in relation to lower limb function. The clusters of items on Touwen's examination which showed increased impairment with increasing duration of flares were those testing 'posture', 'coordination of the extremities', and 'gross motor functions'. Eleven out of the 19 items included in these clusters examine the coordination of legs and feet, while four items are concerned with hand and arm coordination. Similarly, in the Movement ABC Test, all of the 'static and dynamic balance' items were sensitive to the effects of increasing duration of flares with two 'manual dexterity' items showing similar trends. These findings support Volpe's suggestion that periventricular lesions close to the ventricles, such as flares, will have a greater 
effect on the descending axons that control lower limb functioning than the more laterally placed tracts controlling the upper limb, ${ }^{19}$ although their anatomical proximity may produce considerable overlap in the distribution of impairment.

Although not completely comparable, the two previous reports on the association between the persistence of flares and later motor function show marked similarities to the findings of the present study (the inclusion of infants who had both flares and intraventricular haemorrhage/periventricular haemorrhage makes comparison with Fawer and Calame's study more difficult). ${ }^{67}$ While Levene et al did not show statistically significant differences in motor function between children with normal scans and those with prolonged flares, both studies demonstrated that children whose flares lasted for more than two weeks were the most likely to be impaired. In the present study, we have obtained a similar outcome with a carefully selected group of 6 year olds. Moreover, by examining a more complete range of flare duration, we have extended the finding of De Vries et al that even children whose flares last less than two weeks are at an increased risk for developing subtle movement difficulties. ${ }^{4}$

Our findings would suggest that the previous policy of grouping children with flares that last for less than two weeks together with those who have normal scans may be misleading from both a practical and a theoretical viewpoint. At a practical level, our data suggest that it would not be safe to consider children with flares which last less than 14 days as free from risk, particularly as their impairment might affect their every day life activities. At a theoretical level, we need further studies to achieve a better understanding of the effect of transient periventricular lesions on development.

This study was made possible by a grant from the Medical Research Council. We are very grateful to the children, parents, and teachers who so willingly and enthusiastically cooperated with us. We would also like to thank Professor $M$ Healy for his statistical advice.

1 Graham M, Levene MI, Trounce JQ, Rutter N. Prediction of cerebral palsy in very low birthweight infants: prospective ultrasound study. Lancet 1987; ii: 593-6.

2 Trounce JQ, Rutter N, Levene MI. Periventricular leukomalacia and intraventricular haemorrhage in the preterm meonate. Arch Dis Child 1986; 61: 1196-202.

3 De Vries LS, Regev R, Pennock JM, et al. Ultrasound evolution and later outcome of infants with periventricular densities. Early Hum Dev 1988; 16: 255-33.

4 Appleton RE, Lee REJ, Hey EN. Neurodevelopmental outcome of transient neonatal intracerebral echodensities. Arch Dis Child 1990; 65: 27-9.

5 Fawer CL, Calame A. Significance of ultrasound appearances in the neurological development and cognitive abilities of preterm infants at 5 years. Eur $\mathcal{F}$ Pediatr 1991; 150: $515-20$.

6 Levene M, Dowling S, Graham M, Fogelman K, Galton M, Phillips M. Impaired motor function (clumsiness) in 5 year old children: correlation with neonatal ultrasound scans. Arch Dis Child 1992; 67: 687-90.

7 De Vries LS, Dubowitz LMS, Dubowitz V, et al. Predictive value of cranial ultrasound: a reappraisal. Lancet 1985; ii: $137-40$

8 De Vries LS, Eken P, Dubowitz LMS. The spectrum of leukomalacia using cranial ultrasound. Behav Brain Res 1992; 49: 1-6.

9 Touwen BCL. Examination of the child with minor neurological dysfunction. Clinics in developmental medicine. No 71. London: William Heinemann Medical Books, 1979.

10 Sonksen PM, Silver J. The Sonksen-Silver acuity system. Windsor: Keeler Ltd, 1988.

11 Stereo test. Chicago: Stereo Optical Company, 1988.

12 Henderson SE, Sugden D. The movement assessment battery of children. London: The Psychological Corporation, 1992

13 Elliott CD, Murray DJ, Pearson LS. The British ability scales. Windsor: NFER-Nelson Publishing, 1983.

14 Beery KE. Developmental test of visual-motor integration. Cleveland: Modern Curriculum Press, 1989.

15 Rutter $M$. Classification and categorization in child psychiatry. F Child Psychol Psychiatry 1965; 6: 71-83.

16 Rutter M. A children's behaviour questionnaire for completion by teachers: preliminary findings. $\mathcal{f}$ Child Psychol tion by teachers: prelim

17 Siegel S, Castellan NJ. Nonparametric statistics for the behavioural sciences. New York: McGraw-Hill, 1988.

18 Tabachnick BG, Fidell LS. Using multivariate statistics. New York: Harper Collins, 1989.

19 Volpe J. Neurology of the newborn. Major problems in clinical pediatrics. Philadelphia: WB Saunders 1987: 